\title{
Computational modeling of the external tufted cell of the mammalian olfactory bulb
}

\author{
William Erik Sherwood ${ }^{1 *}$, Joe Tien ${ }^{2}$, Ryan Carey $^{3}$, Nancy Kopell ${ }^{1}$ \\ From Nineteenth Annual Computational Neuroscience Meeting: CNS*2010 \\ San Antonio, TX, USA. 24-30 July 2010
}

The glomeruli of the mammalian olfactory bulb are the initial loci of synaptic processing in the olfactory system, and they contain at least three classes of juxtaglomerular (JG) interneurons whose roles in odor processing are not well understood. External tufted (ET) cells constitute one major class of excitatory JG interneurons, and recent experimental studies indicate that they may play a central role in coordinating intraglomerular activity [1]. Among their suggestive properties, ET cells have been found to burst endogenously at theta frequency, to entrain to patterned input at sniffing frequencies, and to synchronize via synaptic and gap junctional mechanisms $[2,3]$. They also appear to be primary mediators of signal transmission between olfactory receptor neurons and mitral cells [4].

We present a single-compartment, Hodgkin-Huxleystyle model of the ET cell which includes those identified membrane currents which are known to be essential for endogenous bursting: spiking sodium and potassium currents, a low-voltage activated T-type calcium current (ICaT), and a persistent sodium current (INaP) [5]. A model variant incorporating an $\mathrm{H}$-type current was also constructed. Passive membrane properties were based on data from the literature, while the kinetics of active currents were obtained from voltage clamp data using the 'full-trace' method of the NEUROFIT software package [6]. The model neuron (versions implemented in PyDSTool [7] and MATLAB) is designed for use in larger scale computational models of the juxtaglomerular circuitry.

We explore the model's parameter space using detailed parameter sweeps and Latin hypercube sampling, demarcating regions of bursting, tonic, and excitable behavior. To study the sensitivity of various functional characteristics to changes in parameter values, we employ specialized smooth optimization methods for bursting neural models

* Correspondence: wesher@bu.edu

${ }^{1}$ Center for BioDynamics, Boston University, Boston, MA 02215, USA
[8]. We find that the half-activation voltages for ICaT and $\mathrm{INaP}$ are most critical for control of interburst period and duty cycle. We also investigate the phase response properties of the ET cell model and its responses to periodic input.

\section{Acknowledgements}

We thank Michael T. Shipley and Shaolin Liu of the University of Maryland for generously sharing their ET cell voltage clamp data, and Allan Willms of the University of Guelph for assistance with NEUROFIT.

\section{Author details}

${ }^{1}$ Center for BioDynamics, Boston University, Boston, MA 02215, USA. ${ }^{2}$ Mathematics Department, Ohio State University, Columbus, OH, 43210, USA. ${ }^{3}$ Department of Biomedical Engineering, Boston University, Boston, MA 02215, USA.

Published: 20 July 2010

\section{References}

1. Hayar A, Karnup S, Ennis M, Shipley MT: External Tufted Cells: A Major Excitatory Element that Coordinates Glomerular Activity. J. Neurosci. 2004, 24(30):6676-6685.

2. Hayar A, Karnup S, Shipley MT, Ennis M: Olfactory Bulb Glomeruli: External Tufted Cells Intrinsically Burst at Theta Frequency and Are Entrained by Patterned Input. J. Neurosci. 2004, 24(5):1190-1199.

3. Hayar A, Shipley MT, Ennis M: Olfactory Bulb External Tufted Are Synchronized by Multiple Intraglomerular Mechanisms. J. Neurosci. 2005, 25(36):8197-8208.

4. De Saint Jan D, Hirnet D, Westbrook GL, Chupak S: External Tufted Cells Drive the Output of Olfactory Bulb Glomeruli. J. Neurosci. 2009, 29(7):2043-2052

5. Liu S, Shipley MT: Multiple Conductances Cooperatively Regulate Spontaneous Bursting in Mouse Olfactory Bulb External Tufted Cells. J. Neurosci. 2008, 28(7):1625-1639.

6. Willms AR: NEUROFIT: Software for fitting Hodgkin-Huxley models to voltage clamp data. J Neurosci Methods 2002, 121:139-150.

7. Clewley R, Sherwood WE, Lamar MD, Guckenheimer J: PyDSTool: An Integrated Simulation, Modeling, and Analysis Package for Dynamical Systems. 2007 [http://sourceforge.net/projects/pydstool].

8. Tien $\mathrm{JH}$, Guckenheimer J: Parameter estimation for bursting neural models. J Comput Neurosci 2008, 24:358-373.

doi:10.1186/1471-2202-11-S1-P128

Cite this article as: Sherwood et al:: Computational modeling of the external tufted cell of the mammalian olfactory bulb. BMC Neuroscience 2010 11(Suppl 1):P128. 